\title{
Loving-Kindness Meditation Improves Relationship Negativity and Psychological Well-Being: A Pilot Study
}

\author{
Bert N. Uchino ${ }^{*}$, Kimberly Bowen ${ }^{1}$, Robert G. Kent de Grey ${ }^{1}$, Timothy W. Smith', \\ Brian R. Baucom ${ }^{1}$, Kathleen C. Light' ${ }^{2}$, Shirley Ray ${ }^{3}$ \\ ${ }^{1}$ Department of Psychology and Health Psychology Program, University of Utah, Salt Lake City, USA \\ ${ }^{2}$ Department of Anesthesiology University of Utah, Salt Lake City, USA \\ ${ }^{3}$ Insight Mindfulness Meditation of Salt Lake, Salt Lake City, USA \\ Email: *bert.uchino@psych.utah.edu
}

Received 5 September 2015; accepted 2 January 2016; published 5 January 2016

Copyright (C) 2016 by authors and Scientific Research Publishing Inc.

This work is licensed under the Creative Commons Attribution International License (CC BY). http://creativecommons.org/licenses/by/4.0/

(c) (i) Open Access

\begin{abstract}
Most interventions on relationships and health have focused on altering positive aspects of relationship such as social support. Given the separability of positive and negative aspects of relationships it is less clear if such interventions can also influence relationship negativity. This pilot study of 9 individuals tested the influence of a novel 6-week loving-kindness meditation (LKM) intervention on changes over time in social support, social negativity, depression, and life satisfaction. Consistent with past work, LKM participants showed increases in perceived support and decreases in depression. Extending prior work, LKM participants also showed decreases in social negativity, which was more closely linked to changes in depression compared to social support. These data suggest the feasibility of using LKM to increase relationship positivity, decrease relationship negativity, and enhance psychological well-being.
\end{abstract}

\section{Keywords}

Social Support, Social Negativity, Loving-Kindness Meditation, Well-Being

\section{Introduction}

The quality of one's social relationships has been reliably-related to both mental and physical health outcomes (Holt-Lunstad, Smith, \& Layton, 2010). As a result, interventions to improve psychological and physical

"Corresponding author.

How to cite this paper: Uchino, B. N., Bowen, K., Kent de Grey, R. G., Smith, T. W., Baucom, B. R., Light, K. C., \& Ray, S. (2016). Loving-Kindness Meditation Improves Relationship Negativity and Psychological Well-Being: A Pilot Study. Psychology, 7, 6-11. http://dx.doi.org/10.4236/psych.2016.71002 
well-being have been attempted to alter relationship processes. Most of this work has focused on positive aspects of relationships such as social support (Hogan, Linden, \& Najarian, 2002). These interventions have used diverse approaches such as social skills training, mobilizing support networks, and fostering supportive interactions among similar others (Hogan et al., 2002). Importantly, many of these social support interventions report positive outcomes (Uchino, 2004).

Much less research in this area has attempted to improve the quality of individual's relationships by focusing on decreasing social negativity (e.g., conflict, insensitivity, interference, Brooks \& Dunkel Schetter, 2011). This is an important issue because positive and negative aspects of relationships are separable dimensions and hence have different antecedent processes (Newsom, Nishishiba, Morgan, \& Rook, 2003). Thus, increasing relationship positivity does not imply that relationship negativity is altered in beneficial ways. Interventions focusing on improving relationship functioning will need to target both positive and negative aspects of relationships.

One promising intervention approach to improving both aspects of relationship functioning is loving kindness meditation (LKM). LKM comes from the Buddhist tradition and focuses on people as the object of attention in order to increase feelings of love, caring, and compassion for the self and others (Kok \& Fredrickson, 2013; Salzberg, 1995). Although LKM has been practiced for centuries (Salzberg, 1995), only recently researchers have tested its implications for well-being. Hutcherson, Seppala, and Gross (2008) found that a few minutes of LKM in a lab setting increased feelings of positivity towards a stranger on both explicit and implicit relationship assessments. One of the most extensive LKM interventions was conducted by Fredrickson and her colleagues (2008). In their intervention, participants were randomly assigned to a wait list or LKM group. Results revealed that LKM was related to greater positive emotions during social interactions and perceptions of social support compared to the control condition (Fredrickson et al., 2008).

The main goal of this pilot study was thus to test whether LKM could also influence relationship negativity. Unlike prior work, this study was unique in that we examined relationship negativity in existing network members whom individuals have a long history of social interactions (Birditt, Miller, Fingerman, \& Lefkowitz, 2009). Participants completed a single arm 6 week prospective LKM intervention study in which measures of social support, social negativity, and psychological well-being were completed pre and post-intervention. Consistent with prior work, we predicted that LKM would increase social support, decrease depression, and increase satisfaction with life. Extending prior work, we also predicted that LKM would decrease relationship negativity. Exploratory analyses also examined the association between LKM-related changes in relationship negativity/ positivity and mental health outcomes.

\section{Method}

\subsection{Participants}

Eleven participants who responded to flyers/advertisements were eligible for the study and agreed to participate (4 men, 7 women). Of these, 2 women dropped out due to the time commitments of the study (82\% retention). Our final sample thus consisted of 9 individuals who completed the 6 weekly LKM workshops. Their ages ranged from 18 to 46, with an average age of 30 years $(S D=11.2)$. Sixty-seven percent of the sample was White with 33\% indicating "other." Reported yearly income varied from $\$ 0$ to $\$ 599(n=2), \$ 2000-\$ 2999(n=1)$, $\$ 3000$ - \$3999 ( $=1), \$ 10,000-\$ 14,999(n=1)$, and $\$ 40,000$ and above $(n=4)$. The education levels of participants were high school graduate $(n=1)$, partial college $(n=5)$, and college graduate $(n=3)$.

\subsection{Procedure}

The LKM intervention was similar to Fredrickson and colleagues (2008) and participants attended a total of 6 weekly one hour LKM workshops. During the weekly meetings, participants engaged in discussion, skills teaching, and practice of relevant material that was led by our LKM meditation educator (Ms. Shirley Ray). Ms. Ray has a Masters of Arts in Liberal Studies degree from Dartmouth College, with a Master Teacher designation from Harvard. She has been a student of meditation for over 30 years and completed the three year Community Dharma Leaders program at Spirit Rock Meditation Center (Marin County, CA).

Consistent with past LKM studies, week one was focused on general meditation habits (e.g., posture, breathing) and directing love and kindness to themselves. Week 2 was also focused on loved ones. Subsequent weeks focused on strangers, acquaintances, and finally more conflicted relationships and all living beings. At least 20 minutes was spent during each weekly session on the actual practice of LKM, 20 mins to check on participant 
progress and answer any questions, and 20 mins of active group discussion about how to incorporate LKM into one's everyday life (Fredrickson et al., 2008). LKM participants were also encouraged to practice LKM at least 5 days a week during the 6 week intervention by using an audio file with guided LKM instructions from each workshop. Daily cooperation with meditation practices was either assessed through brief phone calls or online surveys (see below). Participants were also given homework aimed at helping them incorporate LKM in everyday life including journal entries (e.g., moments of kindness), development of LKM phrases to guide them, and reflective thinking. Questionnaires tapping into relationship processes and mental health were given just prior to the intervention and right after completion of the final LKM workshops (see below).

\subsection{Questionnaires}

Test of negative social exchanges (TENSE). The TENSE contained 18 questions and assessed global interpersonal stress from social network members (e.g., insensitivity, interference). The TENSE appeared to be statistically independent from measures of social support and has been associated with increased psychological distress. The test-retest reliability of the TENSE ranged from 0.65 to 0.80 (Ruehlman \& Karoly, 1991). In the present study, the internal consistency of the TENSE was 0.91 at baseline and 0.95 post-intervention.

Interpersonal support evaluation list (ISEL). The ISEL contained 40 questions and assessed total social support. Cohen, Mermelstein, Kamarck, and Hoberman (1985) reported an internal consistency of 0.87 for the total scale. The reliability of the ISEL has also been established over a 6-month period (Cohen et al., 1985). The internal consistency of the ISEL was 0.91 and 0.92 at baseline and post-intervention, respectively.

Center for Epidemiologic Studies Depression Scale (CES-D). The CES-D is a 20-item scale that assesses depressive symptoms. The Cronbach's alpha was high in both patient and control samples (0.90), with a 4 week test-retest correlation of 0.67 (Radloff, 1977). Internal consistency of the CES at baseline was 0.74, whereas post-intervention it was 0.52 .

Satisfaction With Life Scale (SWLS). The SWLS is a 5 item scale that measures general life satisfaction and is also sensitive to life changes (Pavot \& Diener, 1993). Pavot and Diener (1993) reviewed evidence indicating that the SWLS is characterized by high internal consistency (e.g., 0.89) and a good test-retest reliability (e.g., 4 year test-retest reliability of 0.54 ). In the study, the internal consistency was 0.83 and 0.89 at baseline and postintervention, respectively.

Attendance and cooperation with LKM. Attendance was recorded at each of the 6 LKM workshops. Daily cooperation with LKM during the 6 week period was also obtained via daily reports by asking whether they engaged in LKM or other forms of meditation during the past 24 hours and if so for how many minutes. On average, the 9 individuals who attended the workshops meditated at home an average of 3.3 days a week $(\mathrm{SD}=1.5)$ during the 6 week period. Participants on average also reported meditating 25 minutes per day $(\mathrm{SD}=15)$ during the intervention period.

Statistical Analyses Plan. To examine pre-post changes in our main variables over time we utilized simple paired t-test to account for the repeated measures design. Secondary correlational analyses were conducted to test if changes in the main intervention factors (i.e., social support, social negativity) were related to changes in psychological well-being. In all analyses, we used one-tailed tests of significance given the directional nature of our predictions and because this was a pilot study.

\section{Results}

Replicating prior work, we found that LKM was associated with a significant increase in perceived social support following the intervention $(\mathrm{M}=0.11$, $\mathrm{SD}=0.08$, $\mathrm{t}(8)=4.38, p<0.001$, Cohen's $\mathrm{d}=1.45$, see Table 1 ). We also replicated prior work in finding that LKM was related to decreases in depressive symptoms during the study period $(\mathrm{M}=-3.89, \mathrm{SD}=5.95, \mathrm{t}(8)=1.96, p<0.05$, Cohen's $\mathrm{d}=0.65)$. Although the trend was in the predicted direction, intervention-related changes in satisfaction with life was not significantly different over time $(p=0.19$, Cohen's $d=0.31)$.

The main goal of this study was to test the links between a pilot LKM intervention and relationship negativity. Extending prior work, we found that social negativity decreased during the intervention period $(\mathrm{M}=-0.24$, SD $=0.35$, t $(8)=2.06, p<0.04$; Cohen's $d=0.69$ ). In exploratory analyses we also examined the simple correlation among the study variables to examine if change scores in social negativity or support were more closely linked to change scores in depression and satisfaction with life following the intervention. As shown in Table 2, 
Table 1. Pre-post intervention scores on main study variables.

\begin{tabular}{cccccc}
\hline Variable & Pre & Post & $\mathrm{t}$ & $\mathrm{SE}$ & $p$ \\
\hline Social support & 2.16 & 2.28 & 4.38 & 0.02 & 0.001 \\
Depression & 33.67 & 29.78 & 1.96 & 1.98 & 0.042 \\
Life satisfaction & 4.50 & 4.76 & 0.92 & 0.28 & 0.19 \\
Social negativity & 1.20 & 0.97 & 2.06 & 0.12 & 0.037 \\
\hline
\end{tabular}

Table 2. Correlation matrix of changes in main study variables.

\begin{tabular}{ccccc}
\hline Variable & Social support & Social negativity & Depression & Life satisfaction \\
\hline Social support & 1.00 & & & \\
Social negativity & $-0.04(p=0.46)$ & 1.00 & & \\
Depression & $-0.05(p=0.45)$ & $0.53(p=0.07)$ & 1.00 & \\
Life satisfaction & $0.11(p=0.38)$ & $-0.46(p=0.11)$ & $-0.52(p=0.08)$ & 1.00 \\
\hline
\end{tabular}

replicating prior work we first found that decreases in depression over time were related to increases in life satisfaction $(r=-0.52, p=0.08)$. More important, decreases in social negativity during the intervention were a marginally significant predictor of decreases in depression $(r=0.53, p=0.07)$ and non-significant increases in life satisfaction $(r=-0.46, p=0.11)$. Changes in social support, in comparison, were not related to changes in depression or life satisfaction at the end of the 6 week intervention period ( $r$ 's $=-0.05$ to 0.11 , see Table 2 ).

\section{Discussion}

The main goal of this pilot study was to examine if an LKM intervention could decrease relationship negativity. Consistent with this possibility, we found that LKM significantly decreased overall levels of perceived hostility, insensitivity, interference, and ridicule from others as assessed by the TENSE. Moreover, replicating prior work, LKM was also associated with increases in perceived social support and decreases in depression. These data suggest the potential of LKM to influence relationship processes that have been linked in prior work to both mental and physical health outcomes.

Prior interventions aimed at altering relationships to promote positive health outcomes have mostly focused on positive aspects of relationship such as social support (Hogan et al., 2002). These interventions have used diverse approaches including social skills training, befriending, and support groups with somewhat mixed results (Uchino, 2004). This underscores the need to approach future interventions from novel perspectives. Results from this pilot study suggest that a focus on both relationship positivity and negativity should produce larger effect sizes given the separability of these relationship dimensions (Newsom et al., 2003). Indeed, the effect sizes for this pilot study (Cohen's $d$ and r's) in most cases were close or exceeded the large range. Altering social negativity may also be particularly important as our findings indicate that it was more consistently linked to changes in mental health. In general, by influencing both perceptions of social support and social negativity, LKM holds promise as an intervention strategy although future work would be needed to directly document a link to health outcomes.

One important future question relates to how LKM produces such beneficial relationship changes. There are several cascading cognitive and behavioral mechanisms that might be operating. By focusing on loving-kindness towards all, LKM may provide a cognitive lens that facilitates the processing of more positive and less negative relationship information (Murray, Holmes, \& Griffin, 1996). It is also possible that such a relationship schemata may in turn invoke more positive and less negative relationship exchanges with social network members (Murray et al., 1996). Of course, such satisfying behavioral interactions are in turn likely to further foster greater perceptions of relationship positivity and lower perceptions of relationship negativity.

An additional future research question relates to links between LKM and mindfulness as both are based in the Buddhist tradition (Kok \& Fredrickson, 2013). Mindfulness-based stress reduction attempts to cultivate nonjudgmental awareness, openness, and acceptance (Grossman \& Van Dam, 2011). Across a variety of outcomes, 
mindfulness interventions have been related to positive outcomes (Eberth \& Sedlmeier, 2012). Mindfulness and LKM both focus on being aware of emotional states, especially those that are habitual, hence cultivating the ability to make a conscious choice to seek an alternative state of mind in a familiar situation. Mindfulness and LKM are thus related practices and in many cases mindfulness is used to help initially focus attention so one can be open to loving-kindness (Smalley \& Wintson, 2010). However, mindfulness focuses on attending to mental constructs, while LKM focuses on attending to people and seeks to increase feelings of love, caring, and compassion for the self and others, including more conflicted relationships (Salzberg, 1995). LKM is thus a distinct form of mediation and studies suggest differential mechanisms might be operating between LKM and mindfulness meditation such as feelings of positive affect and social connectedness (Feldman, Greeson, \& Senville, 2010; Kok \& Fredrickson, 2013).

As a pilot study, this research has important limitations. The sample size is necessarily small and included a single arm pre-post design which limits strong inferences. It should be noted that small pilot studies are an important part of intervention development (Thabane et al., 2010) and we were able to replicate prior work on LKM that utilized control groups. Given the small sample, future work would also be needed using more diverse samples of varying socioeconomic status given that meditation studies tends to appeal to certain populations (e.g., White, well-educated; Kok \& Fredrickson, 2013). Finally, research that examines how long these associations are maintained over time is important. The longest follow-up for an LKM study that we are aware is 3 months and some work suggest these links persist primarily for individuals who continue to meditate over time (Fredrickson et al., 2008).

\section{Conclusion}

This pilot study suggests that LKM may be a novel intervention approach to improve well-being by fostering relationship processes. A major benefit is that it appears to be a more comprehensive approach to altering relationship perceptions as it both increased social support and decreased social negativity. This pilot study thus sets the basis for larger randomized control trials which seek to test the generalizability of these results to other samples and outcomes.

\section{References}

Birditt, K. S., Miller, L. M., Fingerman, K. L., \& Lefkowitz, E. S. (2009). Tensions in the Parents and Adult Child Relationship: Links to Solidarity and Ambivalence. Psychology and Aging, 24, 287-295. http://dx.doi.org/10.1037/a0015196

Brooks, K., \& Dunkel-Schetter, C. (2011). Social Negativity and Health. Social and Personality Psychology Compass, 5, 904-918. http://dx.doi.org/10.1111/j.1751-9004.2011.00395.x

Cohen, S., Mermelstein, R. J., Kamarck, T., \& Hoberman, H. M. (1985). Measuring the Functional Components of Social Support. In I. G. Sarason, \& B. Sarason (Eds.), Social Support: Theory, Research, and Application (pp. 73-94). The Hague, Holland: Martinus-Niijhoff. http://dx.doi.org/10.1007/978-94-009-5115-0_5

Eberth, J., \& Sedlmeier, P. (2012). The Effects of Mindfulness Meditation: A Meta-Analysis. Mindfulness, 3, 174-189. http://dx.doi.org/10.1007/s12671-012-0101-x

Feldman, G., Greeson, J., \& Senville, J. (2010). Differential Effects of Mindful Breathing, Progressive Muscle Relaxation, and Loving-Kindness Meditation on Decentering and Negative Reactions to Repetitive Thoughts. Behaviour Research and Therapy, 48, 1002-1011. http://dx.doi.org/10.1016/j.brat.2010.06.006

Fredrickson, B. L., Cohn, M. A., Coffey, K. A., Pek, J., \& Finkel, S. M. (2008). Open Hearts Build Lives: Positive Emotions, Induced through Loving-Kindness Meditation, Build Consequential Personal Resources. Journal of Personality and Social Psychology, 95, 1045-1062. http://dx.doi.org/10.1037/a0013262

Grossman, P., \& Van Dam, N. T. (2011). Mindfulness, by Any Other Name...: Trials and Tribulations of Sati in Western Psychology and Science. Contemporary Buddhism, 12, 219-239. http://dx.doi.org/10.1080/14639947.2011.564841

Hogan, B. E., Linden, W., \& Najarian, B. (2002). Social Support Interventions Do They Work? Clinical Psychology Review, 22, 381-440. http://dx.doi.org/10.1016/S0272-7358(01)00102-7

Holt-Lunstad, J., Smith, T. B., \& Layton, B. (2010). Social Relationships and Mortality: A Meta-Analysis. PLoS Medicine, 7 , 1-20. http://dx.doi.org/10.1371/journal.pmed.1000316

Hutcherson, C. A., Seppala, E. M., \& Gross, J. J. (2008). Loving-Kindness Meditation Increases Social Connectedness. Emotion, 8, 720-724. http://dx.doi.org/10.1037/a0013237

Kok, B. E., \& Fredrickson, B. L. (2013). Meditation and Health: The Search for Mechanisms of Action. Social and Personality Psychology Compass, 7, 27-39. http://dx.doi.org/10.1111/spc3.12006 
Murray, S. L., Holmes, J. G., \& Griffin, D. W. (1996). The Self-Fulfilling Nature of Positive Illusions in Romantic Relationships: Love Is Not Blind, but Prescient. Journal of Personality and Social Psychology, 71, 1155-1180.

http://dx.doi.org/10.1037/0022-3514.71.6.1155

Newsom, J. T., Nishishiba, M., Morgan, D. L., \& Rook, K. S. (2003). The Relative Importance of Three Domains of Positive and Negative Social Exchanges: A Longitudinal Model with Comparable Measures. Psychology and Aging, 18, 746-754. http://dx.doi.org/10.1037/0882-7974.18.4.746

Pavot, W., \& Diener, E. (1993). Review of the Satisfaction with Life Scale. Psychological Assessment, 5, 164-172. http://dx.doi.org/10.1037/1040-3590.5.2.164

Radloff, L. S. (1977). The CES-D Scale: A Self-Report Depression Scale for Research in the General Population. Applied Psychological Measurement, 1, 385-401. http://dx.doi.org/10.1177/014662167700100306

Ruehlman, L. S., \& Karoly, P. (1991). With a Little Flak from My Friends: Development and Preliminary Validation of the Test of Negative Social Exchange (TENSE). Psychological Assessment, 3, 97-104. http://dx.doi.org/10.1037/1040-3590.3.1.97

Salzberg, S. (1995). Loving-Kindness: The Revolutionary Art of Happiness. Boston, MA: Shambhala.

Smalley, S. L., \& Winston, D. (2010). Fully Present: The Science, Art, and Practice of Mindfulness. New York: Da Capo Lifelong Books.

Thabane, L., Ma, J., Chu, R., Cheng, J., Lsmaila, A., Rios, L. P., Robson, R., Thabane, M., Giagregorio, L., \& Goldsmith, C. H. (2010). A Tutorial on Pilot Studies: The What, Why, and How. BMC Medical Research Methodology, 10, 1. http://dx.doi.org/10.1186/1471-2288-10-1

Uchino, B. N. (2004). Social Support and Physical Health: Understanding the Health Consequences of Our Relationships. New Haven, CT: Yale University Press. http://dx.doi.org/10.12987/yale/9780300102185.001.0001 